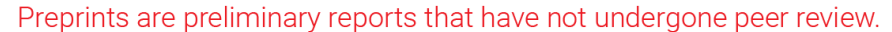 They should not be considered conclusive, used to inform clinical practice, or referenced by the media as validated information. \\ Tropical cyclone climatology change greatly exacerbates US joint rainfall-surge hazard
}

\section{Avantika Gori}

Princeton University

\section{Ning Lin ( $\nabla$ nlin@princeton.edu )}

Princeton University https://orcid.org/0000-0002-5571-1606

\section{Dazhi Xi}

Princeton University

\section{Kerry Emanuel}

MIT https://orcid.org/0000-0002-2066-2082

\section{Article}

Keywords: tropical cyclones, tropical cyclones climatology, rainfall-surge hazard

Posted Date: August 24th, 2021

DOl: https://doi.org/10.21203/rs.3.rs-805581/v1

License: (c) (1) This work is licensed under a Creative Commons Attribution 4.0 International License. Read Full License

Version of Record: A version of this preprint was published at Nature Climate Change on February 3rd, 2022. See the published version at https://doi.org/10.1038/s41558-021-01272-7. 


\title{
Tropical cyclone climatology change greatly exacerbates US joint rainfall-surge hazard
}

\author{
Avantika Gori ${ }^{1}$, Ning Lin ${ }^{* 1}$, Dazhi Xi ${ }^{1}$, Kerry Emanuel ${ }^{2}$ \\ 1Princeton University, Department of Civil \& Environmental Engineering \\ ${ }^{2}$ Massachussetts Institute of Technology, Department of Earth, Atmospheric and Planetary Sciences \\ *Corresponding Author, nlin@princeton.edu
}

\section{Abstract}

Tropical cyclones (TCs) are among the largest drivers of extreme rainfall and surge, but current and future TC joint hazard has not been well quantified. We utilize a physics-based approach to simulate TC rainfall and storm tides and quantify their joint hazard under historical conditions and a future (SSP5 8.5) climate projection. We find drastic increases in the frequency of exceeding joint historical 100-yr hazard levels by 2100, with a 10-36 fold increase along the southern US coast and 30-195 fold increase in the northeast. The joint hazard increase is induced by sea-level rise and TC climatology change; the relative contribution of TC climatology change is higher than that of sea-level rise for $96 \%$ of the coast due to large increases in rainfall. Increasing storm intensity and decreasing translation speed are the main TC change factors that cause higher rainfall and storm tides and up to $25 \%$ increase in their dependence.

\section{Introduction}

25 Coastlines across the globe are vulnerable to the joint occurrence of high sea levels and intense rainfall1-3, which can increase flooding beyond the level predicted by considering either hazard alone and result in a compound flood 4,5 . However, traditional flood risk assessment frameworks have typically focused on storm surge flooding alone, neglecting contributions from rainfall-runoff. Along the US Atlantic and Gulf Coasts, tropical cyclones (TC) are one of the largest drivers of coastal flood losses ${ }^{6,7}$ and are major contributors to compound flood hazard due to their ability to produce extreme storm surges and intense precipitation ${ }^{1,8}$. However, few regional studies of compound flood hazard have explicitly accounted for TC events ${ }^{9}$ due to their sparse occurrence in the historical record and 
34 challenges in representing TCs within reanalysis datasets and typical global circulation 35 models (GCMs).

36 Dynamics between coastal rainfall and storm tides may be impacted in the future 37 due to the combination of sea-level rise (SLR) and changes in storm climatology. Recent 38 projections of future storm climatology change suggest an increase in the probability of 39 joint rainfall-surge events along much of the European coastline, mostly driven by an 40 increase in rainfall hazard ${ }^{10}$. Along the US coastline, previous studies have considered 41 changes in joint hazard resulting from changes in a subset of climate-induced variables, 42 such as $\mathrm{SLR}^{11}$ and changes in river flow ${ }^{12}$ or changes in rainfall ${ }^{9}$. However, it is still unclear 43 how future changes in TC climatology and SLR will alter the severity and spatial variation 44 of joint rainfall-surge hazard across the US Atlantic and Gulf Coasts, what will be the 45 relative contribution of storm climatology change and SLR to changes in the joint hazard, 46 and how changes in TC characteristics are related to changes in rainfall hazard, storm surge 47 hazard, and their dependence.

$48 \quad$ To address these questions, we apply a full probabilistic joint hazard analysis 49 framework to investigate the current and future joint rainfall-surge hazard from TC events 50 impacting the US Atlantic and Gulf Coasts under the combined influence of end-of-21 $1^{\text {st }}$ 51 century high emission scenario SLR (RCP 8.5) ${ }^{13}$ and storm climatology change (SSP5 8.5) $)^{14}$.

52 We utilize a large set of synthetic TCs generated from a statistical-deterministic TC model ${ }^{15}$ 53 forced with reanalysis or GCM output. Synthetic TCs for historical (1980-2005) conditions

54 are downscaled from reanalysis data and used to represent historical joint hazard.

55 Projected future (2070-2100) TCs are downscaled from eight CMIP6 ${ }^{14}$ GCMs, bias-

56 corrected, and combined into a single weighted-average composite projection that

57 represents future storm climatology (see Methods). We simulate storm tides (storm surge

58 plus astronomical tide) for each event with the advanced circulation (ADCIRC)

59 hydrodynamic model ${ }^{16,17}$, using a high-resolution mesh that spans the entire North Atlantic

60 basin and has been previously validated ${ }^{18}$ (Methods). We estimate rainfall fields using the

61 physics-based Tropical Cyclone Rainfall (TCR) model, which has previously been used to

62 assess historical rainfall climatology ${ }^{19,20}$, project changes in rainfall hazard ${ }^{21}$, and simulate

63 flood impacts 22,23 (Methods). To evaluate the impact of SLR, we incorporate spatially- 
64 varied, probabilistic SLR projections for 2100 from ref. ${ }^{13}$, which are based on projections

65 from a suite of CMIP5 GCMs (Methods).

To focus on a particular metric to measure the joint hazard, we define a joint

67 extreme event as one that exceeds both the historical 100-year storm tide (relative to the

68 historical sea level) and the historical 100-year 24-hour rainfall at a given coastal location.

69 Based on the simulations and bivariate extreme value analysis, we quantify the return

70 period of the joint extreme event (henceforth referred to as JRP) in the historical and future

71 climates (see Methods) and show that SLR and TC climatology change cause drastic

72 increases in the frequency of joint extreme events. We quantify the relative importance of

73 the change of different climatological variables (i.e., sea level, storm frequency, rainfall,

74 storm tides, and hazard dependence) in driving the changes in JRP (Methods) and find that

75 TC climatology changes drive larger increases in joint hazard compared to SLR. We further

76 investigate the effect of TC characteristic changes and find an increase in intensity and a

77 decrease in translation speed, which drive the increases in rainfall and surge hazards as

78 well as their dependence. Our findings motivate explicit consideration of TC climatology

79 changes in compound flood hazard analysis.

80

81 Results

\section{Spatial pattern of joint hazard in current and future climate}

83 For each location along the coastline, we quantify the univariate 100 -year storm tide (i.e.

84 the storm tide level that has a $1 \%$ annual probability to be exceeded) and univariate 100-

85 year 24-hour rainfall for the historical period (Fig S1). Using the thresholds of historical

86 100-year storm tide and rainfall, we quantify the probability of joint extreme event

87 occurrence through JRP in the historical climate (1980-2005) and in the future climate

88 (2070-2100). There are large variations in JRP across the US coastline under historical

89 conditions (Fig 1a). The coastlines of the Gulf of Mexico and Southeast Atlantic (up to

90 Chesapeake Bay) have lower JRP, typically ranging from 200-500 years, signifying a higher

91 probability of joint extreme occurrence compared to other regions. JRP increases along the

92 northern Mid-Atlantic (up to Connecticut) due to a decrease in the statistical dependence

93 between storm tide and 24-hour rainfall. Along the New England coastline JRP is much

94 larger than other regions ( $>1000$ years) because in this region the two hazards occur 
95 almost independently. The low correlation between rainfall and storm tides in New

96 England is due to the large tidal constituents that dominate total extreme sea levels

97 compared to TC-induced storm surges.

98 Due to the combination of future storm climatology and SLR, future JRP may

99 decrease to 3-30 years, with higher JRP values along the Gulf of Mexico and Southeast

100 Atlantic (10-30 years) and lower JRP along the Mid-Atlantic and New England region (3-10

101 years; Fig. 1b). The reason for higher future JRP along the southern coastline is because

102 these regions are already prone to extreme rainfall and surges in the historical climate (Fig

103 S1) and the percent increase in the hazard there is smaller than the percent increase for

104 northern regions. Across the entire coastline, JRP decreases drastically compared to its

105 historical values. In general, the change in JRP increases moving from south to north, with

106 the largest decreases in JRP occurring in northern locations. However, even the locations of

107 smallest JRP change still correspond to a 7-fold increase in the frequency of joint events.

108 The southeast Florida coast (i.e., Miami region) is an exception to the spatial trend of future

109 JRP. Here, the historical JRP is 600 years and the future JRP is 3 years, resulting in a JRP

110 change that is much greater than the JRP change for the rest of the Southeast Atlantic. The

111 reason for the large change in JRP in the Miami region is because storm tides and rainfall

112 are not highly correlated in the historical period, but large increases in rainfall hazard and

113 SLR in the future cause the joint extreme sea level and rainfall thresholds to be exceeded

114 frequently.

115 The projection of JRP is associated with statistical and physical modeling

116 uncertainties; Figure 2 depicts the median JRP estimate (as discussed above) and 95\%

117 boot-strapped sampling uncertainty bounds under historical (gray) and composite future

118 (blue) conditions and the JRP estimates from individual GCMs for representative coastal

119 locations. The sampling uncertainty ranges of the composite future JRP (blue boxes) are

120 much smaller than the historical uncertainties, since joint exceedances are more frequent

121 in the future period and consequently JRP can be estimated with less sampling uncertainty.

122 The variations in JRP estimates among different models are primarily due to differences in

123 the future projected TC frequency and intensity. MPI, MRI, and GFDL consistently predict

124 smaller decreases in JRP since these GCMs project low/no increase in storm frequency (Fig

125 S2) and low-moderate increases in storm intensity (Fig S3). Conversely, ECEARTH and IPSL 
126 consistently predict large decreases in JRP since both models project the highest increases

127 in storm frequency and intensity. The variations among the GCMs are consistent for the

128 entire coastline (Fig. S4). Although there is a relatively large inter-model range of future

129 JRP estimates, especially for locations in the Gulf of Mexico, even the most conservative

130 GCM (i.e., MPI) projects large increases in future joint hazard.

\section{Drivers of joint hazard change}

133 The change in JRP can be driven by three mechanisms: 1) changes in storm frequency, 2)

134 marginal changes in rainfall totals and/or extreme sea level driven by TC climatology

135 changes and SLR, and 3) changes in the statistical dependence between extreme rainfall

136 and storm surges. To understand the relative contribution to changes in JRP from each

137 mechanism, we calculate the isolated impact of changes in storm frequency, rainfall hazard,

138 storm tide hazard, hazard dependence, and SLR, by adjusting each variable to its future

139 value or distribution one at a time and calculating the resulting JRP. In Figure 1c we plot

140 the single variable that causes the largest decrease in JRP at each coastal location. Across

141 the Gulf of Mexico and Florida coastline, the increase in $24 \mathrm{hr}$ rainfall is the largest driver of

142 changes in JRP, while the increase in storm frequency has the largest impact on JRP change

143 for parts of the Southeast and Mid-Atlantic. Along the upper Mid-Atlantic and New England

144 coastline, SLR causes the largest decrease in future JRP. For the select locations, we show

145 the relative impact on JRP change of each variable and the combined impact of all storm

146 climatology variables (TCC) (Fig 3). Across all locations in Fig 3 the change in marginal

147 rainfall distribution is among the largest contributor to the change in JRP, since all GCMs

148 project significant increases in rainfall totals (Fig S5) due to both the increased saturation

149 specific humidity of the warmed environment and the projected increase in TC intensity.

150 Other studies have also projected large increases in the frequency of intense (> $80 \mathrm{~mm} / \mathrm{d}$ )

151 TC rainfall ${ }^{24}$, and up to $30 \%$ increase (under RCP 4.5) in North Atlantic TC rainfall rates due

152 to projected increases in TC intensity ${ }^{25}$. In contrast to the large rainfall impact, the change

153 in marginal storm tide distribution has small impact on the change in JRP for northern

154 locations and a small to moderate impact on JRP change for locations along the Gulf of

155 Mexico. The relative impact of SLR on JRP change generally increases moving south to

156 north, with the largest impact at Portland, ME. Importantly, the total storm climatology 
157 changes drive large increases in joint hazard across all locations. The TCC impact on JRP is

158 larger than the SLR impact for $96 \%$ of locations along the coastline.

159 The change in the dependence between hazards also causes a small to moderate

160 decrease in JRP for most locations in Figure 3, indicating that the extremes of the two

161 hazards are projected to become more dependent in the future climate. To further examine

162 the change in hazard dependence, Figure 4a shows the conditional probability of 24-hour

163 rainfall exceeding the $90^{\text {th }}$ percentile given a storm tide that exceeds the $90^{\text {th }}$ percentile,

164 calculated for the historical period. The conditional probability is a representation of the

165 tail dependence between the hazards, as higher conditional probability corresponds to

166 higher tail dependence. The eastern Gulf of Mexico and Chesapeake Bay exhibit the

167 strongest dependence between hazards, the western Gulf of Mexico and Southeast Atlantic

168 have moderate hazard dependence, and the Mid-Atlantic and New England have relatively

169 low dependence. Figure $4 \mathrm{~b}$ shows the composite change in the conditional probability from

170 the historical to future climate, with areas of red (blue) indicating increases (decreases) in

171 dependence. With the exception of the eastern Gulf of Mexico and Chesapeake Bay, most

172 regions are projected to have higher dependence between extreme rainfall and storm tides

173 in the future. Specifically, the lower Texas, Georgia, North Carolina, and New Jersey

174 coastlines are projected to experience the largest strengthening of hazard dependence in

175 the future, resulting in up to 0.2 increase in the conditional probability (Fig. 4b). Along the

176 eastern Gulf of Mexico there is almost no change in the dependence strength, which is

177 because the two hazards are already highly correlated in the historical climate (Fig 4a) and

178 will remain similarly correlated in the future climate. The Chesapeake Bay stands as an

179 outlier, and it is the only location where the dependence strength between hazards

180 decreases in the future climate (discussed below).

182 Changes in dominant TC storm characteristics

183 Since TC climatology change is the dominant contributor to JRP change, we investigate how

184 projected changes in TC storm characteristics drive changes in rainfall accumulations, peak

185 storm surges, and their dependence at the coast. After investigating correlations between

186 each hazard and storm intensity, approach angle, translation speed, and landfall location

187 and quantifying projected changes in each storm characteristic, we find that storm 
188 intensity and translation speed are both projected to change significantly in the future (Fig $1895 \mathrm{a}$ and 5b, respectively) and are significantly correlated with rainfall and/or storm tide (Fig $1905 \mathrm{c}$-f). For the vast majority of the coastline, both the peak storm tide and 24-hour rainfall 191 are significantly correlated with TC intensity, although the strength of correlation is higher 192 for rainfall (Fig 5c-d). The 24-hour rainfall is also strongly negatively correlated with storm 193 translation speed (Fig 5f), as slower moving storms will drop more rainfall in a given 194 coastal location than faster moving storms. The peak storm tide is not strongly correlated 195 with translation speed (Fig 5e), since both slow and fast moving storms can generate high 196 surges, and the additional wind speed contribution from fast moving storms is generally 197 small compared to the cyclonic wind speed. Under future storm climatology, the $90^{\text {th }}$ 198 percentile of TC intensity is projected to increase by 15-30\% along the Gulf of Mexico and 199 Southeast Atlantic, 30-50\% along the Mid-Atlantic, and 20-30\% along the New England 200 coastline (Fig 5a). The vast majority of previous studies also project an increase in North 201 Atlantic TC intensity, and many predict an increase in the frequency of high intensity 202 (category 3-5) TCs ${ }^{26}$. We also find a large future reduction in the translation speed of 203 storms that exceed the $90^{\text {th }}$ percentile intensity (Fig 5b). For all regions except New 204 England, storms that exceed $90^{\text {th }}$ percentile intensity are likely to move $20-30 \%$ slower in 205 the future than in the historical period. The decrease in translation speed found here is 206 consistent with previous work examining changes in translation speed in the historical 207 record ${ }^{27}$ and projections of TC translation speed under future climate conditions ${ }^{28-30}$. The 208 increase in storm intensity coupled with the decrease in translation speed drives an 209 increased likelihood to observe both extreme rainfall and extreme storm tide in the future 210 and increases the upper tail dependence between the hazards. By comparing Figure $4 \mathrm{~b}$ 211 with Figures 5a-b it is clear that most regions experiencing a significant increase in the 212 hazard dependence also experience significant increases in storm intensity and decreases 213 in translation speed. The Chesapeake Bay is a notable exception, since the hazards are 214 projected to become less dependent in the future even though there is an increase in TC 215 intensity and decrease in translation speed. In the future a larger number of intense storms 216 are projected to approach the coast north of the Bay opening. These storms do not induce 217 high storm surges within the Bay since the cyclonic winds are pointed away from the coast, 
218 but they still induce extreme rainfall. Thus, the increase in the number of these types of 219 storms causes a decrease in the hazard correlation at this location in the future climate.

\section{Discussion}

222 The results presented here provide new insight into how the spatial pattern of TC hazards

223 and their co-occurrence may evolve in the future under a combination of SLR and changing

224 storm climatology. In particular, we project large increases in joint hazard across the US

225 East and Gulf coasts, with the most extreme increases (up to 195-fold decrease in JRP)

226 occurring along the Mid-Atlantic and New England coastlines. We also find that the impact

227 of storm climatology change on joint hazard is larger than the SLR impact for $96 \%$ of the 228 coastline. This is an important finding, since previous work that examined the influence of

229 storm climatology change on extreme sea level change found large impacts at low latitudes

230 but small impacts at high latitudes ${ }^{31}$. Here, we find that storm climatology change is a

231 dominant contributor to future joint surge-rainfall hazard at northern coastal locations,

232 mostly due to projected increases in rainfall hazard. Lastly, we find that the statistical

233 dependence between extreme rainfall and storm tide increases in the future for large

234 swaths of the coastline, resulting in a higher probability to observe multi-hazard extremes

235 during future storm events. This finding is significant since many previous studies of future 236 compound flooding have neglected potential increases in hazard dependence $9,11,12,32$, which 237 could underestimate compound flood risk.

238 The findings presented here are associated with inevitable uncertainties. We utilize 239 a single TC model to downscale all GCMs and reanalysis data, and the model predicts a 240 significant increase in future TC frequency for five of the eight GCMs. Although a few other 241 studies 33,34 have also predicted increases in TC frequency, the majority of studies predict a 242 decrease or no change in North Atlantic storm frequency ${ }^{26}$. However, the main findings of 243 our study are unchanged even if we assume no change in future TC frequency. The future 244 JRP change calculated by holding TC frequency constant at the historical level is slightly 245 lower at each coastal location (up to 149-fold decrease in JRP; see comparison in Fig S6), 246 but the spatial trends (i.e. higher JRP change in the north compared to the south) are 247 unchanged. The relative importance of TC climatology change compared to SLR also 248 remains similar when assuming constant frequency, and TC climatology change still causes 
249 a larger JRP change than SLR for $84 \%$ of the coastline. The reason our results are relatively

250 unchanged if we neglect frequency change projections is because the increase in TC

251 hazards and their joint occurrence is largely driven by projected increases in TC intensity

252 and decreases in translation speed.

253 Although the findings from this work cannot directly predict future compound flood

254 hazard, which must be quantified using high-resolution coastal inundation models, we

255 provide evidence that joint rainfall-surge extreme events could become an increasing

256 threat to coastal communities in the future. Our modeling results and characterization of

257 joint rainfall-surge probability distributions can be used to develop flood mapping

258 scenarios $^{35}$ for regional ${ }^{9,36}$ or local-scale ${ }^{37-39}$ flood models to assess the impact of joint

259 rainfall-surge occurrence on coastal flooding in a changing climate.

261 Methods

262 Data

263 We generated 5018 synthetic TC tracks for the historical time period (between 1980 and

264 2005), based on the National Centers for Environmental Prediction (NCEP) reanalysis ${ }^{40}$.

265 We then generated 4400 synthetic TCs for the historical period (1984-2005) and 6200 TCs

266 for the future period (2070 to 2100) under the Shared Socioeconomic Pathway (SSP) 5, 8.5

267 emission scenario ${ }^{14}$ based on each of eight CMIP $6^{14}$ climate models: Canadian Earth System

268 Model (CANESM), Centre National de Recherches Météorologiques (CNRM), EC-Earth

269 Consortium Model (ECEARTH), Geophysical Fluid Dynamics Laboratory Climate Model

270 (GFDL), The Institute Pierre Simon Laplace Climate Model (IPSL), Model for

271 Interdisciplinary Research on Climate (MIROC), Max Planck Institute Earth System Model

272 (MPI), and Meteorological Research Institute Earth System Model (MRI).

\section{Synthetic TCs}

275 The statistical/deterministic TC model ${ }^{15}$, which has been widely applied for TC hazard

276 assessment $22,31,41-43$, generates synthetic events based on data about the large-scale

277 environment and can be forced with either reanalysis data or projections from GCMs.

278 Vortices are randomly seeded based on historical genesis locations and moved according to

279 the large-scale environmental winds plus a beta-drift correction ${ }^{44}$. TC intensity is estimated 
at each time step based on the Coupled Hurricane Intensity Prediction System (CHIPS), which is an axisymmetric vortex model coupled to a 1D ocean model ${ }^{45}$. For each TC the outer radius at which the cyclonic wind speed goes to zero (henceforth outer radius) is randomly drawn from an empirical lognormal distribution ${ }^{46}$. We neglect the variation in outer radius size over the $\mathrm{TC}$ lifetime ${ }^{47}$ since previous work has shown the outer radius variation to be relatively small ${ }^{48}$. Using the CHIPS-estimated intensity and outer radius, we estimate the radius to maximum winds based on a theoretical wind model that links the outer descending region of the TC with the inner ascending region ${ }^{48}$. We assume no change in the distribution of TC outer size for the future climate since historical trend analysis for the North Atlantic basin found no statistically significant changes in TC size over time ${ }^{49}$. Moreover, an analysis of dynamically-downscaled TCs based on RCP 4.5 end of century forcing found nearly constant outer radius compared to the historical period ${ }^{50}$.

\section{Bias Correction}

294 The downscaled TCs from each GCM may be biased compared to the NCEP-downscaled

295 TCs, and biases within the TC characteristics can propagate to become biases in the hazard

296 estimation. TC intensity and annual frequency are both important drivers of coastal flood

297 risk, and both variables are likely to be biased due to the GCM projections and the method

298 of downscaling. Therefore, we perform bias correction at the storm level based on the

299 difference between the NCEP TC intensity distribution and the GCM-predicted intensity

300 distribution for the historical period. We then bias correct the annual TC frequency

301 (independently from the intensity bias correction) at each location based on the NCEP-

302 downscaled historical frequency and the GCM-downscaled historical frequency. Using our

303 method of bias correction, we avoid multivariate bias correction on the modeled storm

304 tides and rainfall, which often fails to preserve the entire dependence structure between

305 hazards ${ }^{51}$. Additionally, bias correction at the storm level is computationally efficient, while

306 bias correction at the hazard level requires performing intensive hydrodynamic

307 simulations for thousands of historical period GCM TCs.

308 Specifically, to correct the GCM-projected TC intensity (Vmax) of each storm set, we

309 first utilize the quantile delta mapping (QDM) approach described in ref. ${ }^{52}$ applied to each

310 location along the coast. Essentially, the change between the GCM-projected future (2070- 
311 2100) and historical (1984-2005) downscaled Vmax quantiles is added to the NCEP-

312 downscaled historical quantiles to create a corrected future Vmax distribution for each

313 GCM model at each location. Then by the principle of importance sampling53 the GCM-

314 projected storms are weighted and re-sampled with weights corresponding to the ratio of

315 the corrected Vmax probability density to the GCM-projected Vmax probability density. By

316 doing weighted re-sampling of the storms at each location we are able to match the

317 corrected future Vmax distribution and consequently generate a storm set at each location

318 that is unbiased with respect to the intensity distribution. Figure S7 shows the bias

319 correction procedure applied at a sample location for a sample GCM, demonstrating that

320 after weighting/re-sampling the target Vmax distribution is matched accurately. After

321 correcting the Vmax distribution, we bias correct TC frequency by adding the GCM-

322 predicted frequency change to the NCEP-derived frequency at each location.

323

\section{Hydrodynamic Modeling}

325 We simulate TC storm tides using the 2D depth-integrated version of the ADvanced

326 CIRCulation (ADCIRC) model ${ }^{16,17}$. We utilize an unstructured computational mesh

327 developed by ref. ${ }^{18}$ that spans the entire North Atlantic basin and has resolution varying

328 from $>50 \mathrm{~km}$ in the deep ocean to $\sim 1 \mathrm{~km}$ near the coastline. Eight tidal constituents are

329 incorporated as periodic boundary conditions at the ocean boundaries of the mesh, and

330 tidal data are obtained from the global model of ocean tides TPXO8-ATLAS ${ }^{54}$. Wind and

331 pressure fields are developed based on the Vmax and radius to maximum wind (Rmax) of

332 each synthetic TC and physics-based parametric models ${ }^{55,56}$. Further details regarding the

333 mesh formulation, tidal forcing, and wind/pressure models are documented in ref. ${ }^{18}$.

334 Simulated storm tides from the model configuration utilized in this study were compared

335 against observed water levels for 191 historical TCs impacting the US East and Gulf Coasts,

336 and the model was found to satisfactorily reproduce peak storm tides (with an average

337 root mean square error of $0.31 \mathrm{~m}$ and Willmott skill ${ }^{57}$ of 0.90$)^{18}$. In this study we do not

338 account for wave setup since the computational expense of coupling a spectral wave model

339 with the ADCIRC model would prevent a large-scale Monte Carlo risk assessment. For each

340 TC we extract peak storm tides at nodes along the coastline that are spaced roughly $25 \mathrm{~km}$

341 apart. 


\section{Rainfall Modeling}

343 We estimate rainfall fields from each synthetic TC using the Tropical Cyclone Rainfall (TCR)

344 model described in refs ${ }^{19}$. TCR is a physics-based model that simulates convective TC

345 rainfall by relating the precipitation rate to the total upward velocity within the TC vortex.

346 Vertical velocity is estimated by taking into account frictional convergence, topographic

347 forcing, vortex stretching, baroclinic effects, and radiative cooling. TCR has been previously

348 utilized in risk assessment studies ${ }^{21,22}$ and was recently compared against observed TC

349 rainfall across the US ${ }^{20,43}$. It was found in ref. ${ }^{20}$ that TCR simulates the rainfall climatology

350 of coastal regions with relatively good accuracy, although it underperforms in inland and

351 mountainous regions. TCR does not simulate outer TC rain bands, which are three-

352 dimensional in nature and cannot be directly simulated with an axisymmetric model.

353 Nevertheless, a recent study modeled compound flooding using TCR-predicted rainfall

354 fields for several historical events and found that TCR rainfall produced similar flood

355 depth/extent compared to using radar rainfall forcing ${ }^{22}$. In our study, we utilize area-

356 averaged TCR rainfall over each coastal catchment delineated according to USGS hydrologic

357 units (HUs) ${ }^{58}$, and each coastline point is paired with its upstream coastal catchment. We

358 utilize the maximum 24-hour rainfall accumulation (over the catchment) from each storm

359 event as our rainfall metric because the 24-hour storm duration is frequently used for

360 rainfall risk assessment studies ${ }^{59}$.

\section{Sea Level Rise Projections}

363 We incorporate probabilistic, localized sea level rise projections from ref. ${ }^{13}$ for 2100

364 considering the RCP 8.5 emission scenario. In ref. ${ }^{13}$ sea level rise probability distributions

365 are developed for tide gauge locations across the globe by taking into account ice sheet

366 components (Greenland, West Antarctic, and East Antarctic), glacier and ice cap surface

367 mass balance, thermal expansion and oceanographic processes, land water storage, and

368 other non-climatic factors. Sea level changes due to thermal expansion and oceanographic

369 processes are based on ensemble mean projections from a suite of CMIP5 GCMs. For each

370 point along the coastline, we select the nearest tide gauge and adopt the probability

371 distribution specified by ref. ${ }^{13}$. 
We treat TC climatology change and SLR as independent, although they may be

373 significantly correlated. Ref ${ }^{60}$ found a significant correlation between SLR and changes in

374 power dissipation index (an integrated measure of TC intensity, frequency, and duration)

375 for the North Atlantic, suggesting that large increases in mean sea level are more likely to

376 co-occur with larger increases in TC hazard. By neglecting correlations between SLR and

377 climatology changes our results may underestimate the composite (weighted-average)

378 change in climatology and SLR, and consequently represent a conservative estimate of joint

379 hazard change.

\section{Statistical Analysis of Joint Hazard}

382 We conduct statistical analysis on the pairs of modeled storm tides (or storm tides plus

383 SLR) and 24-hr rainfall at each location along the coastline to quantify their marginal and 384 joint hazard.

385 The marginal distributions of both rainfall and storm tides are often characterized 386 by a long tail representing the rare but extreme events ${ }^{41,42}$. The heavy tail can be modeled 387 with a Peaks-Over-Threshold approach, where the probability above a high threshold is 388 estimated by a Generalized Pareto (GP) distribution ${ }^{61}$. We fit marginal GP distributions using the maximum likelihood method ${ }^{61}$ for the rainfall and storm tides at each location, and the threshold is set by numerically minimizing the root mean square error between the

392 theory, a logistic model can be used to estimate the joint distribution of two GP variables 393 such that their bivariate CDF takes the form ${ }^{61,62:}$

$$
G(x, y)=\exp \left\{-\left(\tilde{x}^{-1 / \alpha}+\tilde{y}^{-1 / \alpha}\right)^{\alpha}\right\}
$$

395 Where $\tilde{x}$ and $\tilde{y}$ are the Fréchet-transformed versions of the variables $x$ and $y$, and $\alpha$ is a 396 parameter that quantifies the strength of the dependence between the variables $(\alpha \rightarrow 0$ 397 signifies complete dependence and $\alpha=1$ complete independence). At each location we fit 398 the bivariate distribution of extreme storm tide and rainfall, based on their respective GP 399 thresholds, using a censored maximum likelihood approach ${ }^{62}$ (within the "evd" R400 package ${ }^{63}$ ). The bivariate logistic model employed here has previously been utilized to 401 model dependence between rainfall and storm surges $2,62,64,65$. 
After characterizing the marginal and joint distributions of rainfall and storm tides at each coastline location, we quantify the return period (inverse of the annual exceedance

404 probability) of jointly extreme events. For each location, we model TC occurrence as a

405 Poisson Process with arrival rate $\lambda$ per year. The basin arrival rate is a parameter of the $406 \mathrm{TC}$ model ${ }^{15}$ and is calibrated to match the observed occurrence rate in the North Atlantic 407 basin for the historical period. The location-specific arrival rate $(\lambda)$ is an adjustment of the 408 basin arrival rate according to the proportion of storms passing within $200 \mathrm{~km}$ of each 409 location. We define $x_{T}, y_{T}$ as the marginal 100-year storm tide and 100-year rainfall, 410 defined in the historical period. Then the return period of an event that jointly exceeds $x_{T}$ 411 and $y_{T}$ (henceforth labeled JRP) is calculated as follows:

$$
J R P=\frac{1}{1-e^{-\lambda P}}
$$

413 Where $\mathrm{P}$ is the joint exceedance probability:

$$
P=1-\operatorname{Pr}\left(X \leq x_{T}\right)-\operatorname{Pr}\left(Y \leq y_{T}\right)+G\left(x_{T}, y_{T}\right)
$$

415 Where $\mathrm{G}$ is defined in equation 1.

416 We quantify JRP under the current and future storm climates, by fitting marginal

417 and joint distributions to storm tide and rainfall pairs from NCEP or each GCM-derived

418 storm dataset, with $x_{T}, y_{T}$ defined from the historical period. We estimate the sampling

419 uncertainty bounds of the JRP estimates by implementing a bootstrapping approach with

420500 iterations for each location and each GCM. For each iteration we re-sample (with

421 replacement) pairs of modeled storm tides and rainfall, fit the univariate and joint

422 distributions and re-calculate JRP. We also create a composite JRP projection for the future

423 climate using a weighted average across all GCM storm sets, where the weights of each GCM

424 are based on their Willmott skill ${ }^{57}$ in matching the NCEP TC intensity return level curve in 425 the historical period (Fig. S8). To additionally account for SLR impacts, we randomly draw 426 from the SLR probability distribution specified for each coastline location and add it to the 427 modeled peak storm tide for each event. We apply a standard bootstrapping approach with 428500 iterations at each location and for each GCM storm set to quantify the sampling 429 uncertainty from the synthetic storm set and the SLR distribution. 


\section{Attribution of Changes in Joint Hazard}

432 To quantify the isolated impact of various climate factors on changes in joint rainfall-surge

433 hazard, we adjust a single factor at a time and then re-calculate JRP. To quantify the

434 isolated impact of SLR on changes in JRP, we randomly draw SLR values from location-

435 specific probability distributions ${ }^{13}$ and add them to the historical rainfall-storm tide pairs.

436 The impact of changes in future storm frequency is quantified by simply changing the value

437 of $\lambda$ in equation 2 to reflect the future period frequency. Because storm tide and rainfall

438 are dependent, we quantify the impact of changes in (1) marginal rainfall distribution, (2)

439 marginal storm tide distribution, and (3), dependence between hazards through quantile-

440 matching. We calculate $F_{r, h}$ and $F_{s, h}$ which are the historical rainfall $\left(r_{h}\right)$ and storm tide (

$441 S_{h}$ ) cumulative distribution functions (CDFs), and $F_{r, f}$ and $F_{s, f}$, which are the future

442 CDFs. Given historical pairs of rainfall and storm tide $\left(r_{h}, s_{h}\right)$ we can evaluate the impact of

443 changes in rainfall hazard by changing $r_{h}$ values to $r_{h}^{*}=F_{r, f}^{-1}\left(F_{r, h}^{-1}\left(r_{h}\right)\right)$ so that the

444 magnitude of rainfall is increased according to the future period rainfall distribution but

445 the storm tide $\left(s_{h}\right)$ values and dependence between hazards are unchanged. We similarly

446 calculate the storm tide values $\left(s_{h}^{*}\right)$ while keeping the rainfall values $\left(r_{h}\right)$ constant to

447 evaluate the impact of increases in storm tide on JRP change. The methodology above

448 guarantees the rank correlation between TC rainfall and surge is unchanged. To measure

449 the impact of changes in hazard dependence ( $\alpha$ in equation 1 ), we adjust the future rainfall

450 and storm tide pairs $\left(r_{f}, s_{f}\right)$ as follows: $r_{f}^{*}=F_{r, h}^{-1}\left(F_{r, f}\left(r_{f}\right)\right), \quad s_{f}^{*}=F_{s, h}^{-1}\left(F_{s, f}\left(s_{f}\right)\right)$. The

451 adjusted values of rainfall and storm tide are reduced according to their historical

452 distributions, but the dependence between hazards is based on the future period

453 climatology.

454

455 Data availability statement: 
456 The data generated from this study are deposited to the NSF DesignSafe-CI and can be

457 accessed online (https://www.designsafe-ci.org/\}; link to the dataset will be provided 458 upon publication).

460 Code availability statement:

461 The codes for marginal and bivariate extreme value analysis are deposited to the NSF

462 DesignSafe-CI and can be accessed online (https://www.designsafe-ci.org/); link to the 463 dataset will be provided upon publication).

\section{Acknowledgements}

466 A.G was supported by a National Defense Science \& Engineering Graduate (NDSEG)

467 fellowship from DoD, N.L. and D.X. were supported by National Science Foundation (NSF)

468 grant ICER-1854993, and K.E. was supported by NSF grant ICER-1854929.

\section{Author Contributions}

471 A.G. and N.L designed the study and N.L supervised the modeling and analysis. A.G.

472 performed the hydrodynamic modeling and statistical analysis. A.G. and D.X. performed the 473 rainfall modeling. K.E. modeled the synthetic tropical cyclones. All authors contributed to 474 writing and editing the manuscript.

\section{References}

477 1. Wahl, T., Jain, S., Bender, J., Meyers, S. D. \& Luther, M. E. Increasing risk of compound 478 flooding from storm surge and rainfall for major US cities. Nat. Clim. Chang. 1-6 (2015). doi:10.1038/NCLIMATE2736

480 2. Wu, W. et al. Mapping Dependence Between Extreme Rainfall and Storm Surge. J. 481 Geophys. Res. Ocean. 123, 2461-2474 (2018).

482 3. Lai, Y., Li, J. \& Gu, X. Global compound floods from precipitation and storm surge : 483 Risks and physical mechanisms. J. Clim. (2021). doi:10.1175/JCLI-D-21-0050.1.

484 4. Santiago-Collazo, F., Bilskie, M. V. \& Hagen, S. C. A comprehensive review of 485 compound inundation models in low-gradient coastal watersheds. Environ. Model. 486 Softw. 119, 166-181 (2019). 
487 5. Zscheischler, J. et al. A typology of compound weather and climate events. Nat. Rev. 488 Earth Environ. (2020). doi:10.1038/s43017-020-0060-z

489 6. Hallegatte, S., Green, C., Nicholls, R. J. \& Corfee-Morlot, J. Future flood losses in major $490 \quad$ coastal cities. Nat. Clim. Chang. 3, 802 (2013).

491 7. Peduzzi, P. et al. Global trends in tropical cyclone risk. Nat. Clim. Chang. 2, 289-294 (2012).

493 8. Orton, P. M. et al. Flood hazard assessment from storm tides, rain and sea level rise for a tidal river estuary. Nat. Hazards (2018). doi:10.1007/s11069-018-3251-x

9. Bates, P. D. et al. Combined Modeling of US Fluvial, Pluvial, and Coastal Flood Hazard Under Current and Future Climates. Water Resour. Res. 57, 1-29 (2021).

10. Bevacqua, E. et al. Higher probability of compound flooding from precipitation and storm surge in Europe under anthropogenic climate change. Sci. Adv. 5, 1-8 (2019).

11. Moftakhari, H. R., Salvadori, G., AghaKouchak, A., Sanders, B. F. \& Matthew, R. A. Compounding effects of sea level rise and fluvial flooding. Proc. Natl. Acad. Sci. 114, 9785-9790 (2017).

503

12. Ghanbari, M., Arabi, M., Kao, S., Obeysekera, J. \& Sweet, W. Climate Change and Changes in Compound Coastal-Riverine Flooding Hazard Along the U . S . Coasts. Earth's Futur. doi:10.1029/2021EF002055

13. Kopp, R. E. et al. Probabilistic 21st and 22nd century sea-level projections at a global network of tide-gauge sites. Earth's Futur. 2, 383-406 (2014).

508

14. O'Neill, B. C. et al. The Scenario Model Intercomparison Project (ScenarioMIP) for CMIP6. Geosci. Model Dev. 9, 3461-3482 (2016).

511 16. Luettich, R. A., Westerink, J. J. \& Scheffner, N. W. ADCIRC: An advanced three512 dimensional circulation model for shelves, coasts, and estuaries. Report 1: Theory and 513 methodology of ADCIRC-2DDI and ADCIRC-3DL. (1992).

514 17. Westerink, J. J., Luettich, R. A., Blain, C. A. \& Scheffner, N. W. ADCIRC: An advanced three-dimensional circulation model for shelves, coasts, and estuaries. Report 2: User's Manual for ADCIRC-2DDI. (1992).

517 18. Marsooli, R. \& Lin, N. Numerical Modeling of Historical Storm Tides and Waves and 
518 Their Interactions Along the U.S. East and Gulf Coasts. J. Geophys. Res. Ocean. 38443874 (2018). doi:10.1029/2017JC013434

520 19. Zhu, L., Quiring, S. M. \& Emanuel, K. A. Estimating tropical cyclone precipitation risk in Texas. Geophys. Res. Lett. 40, 6225-6230 (2013).

522 20. Xi, D., Lin, N. \& Smith, J. Evaluation of a physics-based tropical cyclone rainfall model 523 for risk assessment. J. Hydrometeorol. 21, 2197-2218 (2020).

524 21. Emanuel, K. Assessing the present and future probability of Hurricane Harvey's 525 rainfall. Proc. Natl. Acad. Sci. 0, 201716222 (2017).

526 22. Gori, A., Lin, N. \& Xi, D. Tropical Cyclone Compound Flood Hazard Assessment: From Investigating Drivers to Quantifying Extreme Water Levels. Earth's Futur. 8, (2020).

528 23. Lu, P., Lin, N., Emanuel, K., Chavas, D. \& Smith, J. Assessing Hurricane Rainfall Mechanisms Using a Physics-Based Model: Hurricanes Isabel (2003) and Irene (2011). J. Atmos. Sci. 75, 2337-2358 (2018).

531 24. Bacmeister, J. T. et al. Projected changes in tropical cyclone activity under future $532 \quad$ warming scenarios using a high-resolution climate model. Clim. Change 146, 547$533560(2018)$.

534 25. Liu, M., Vecchi, G. A., Smith, J. A. \& Knutson, T. R. Causes of large projected increases 535 in hurricane precipitation rates with global warming. npj Clim. Atmos. Sci. 2, 1-5 (2019).

537 26. Knutson, T. et al. Tropical cyclones and climate change assessment part II: projected response to anthropogenic warming. Bull. Am. Meteorol. Soc. 100, 1987-2007 (2019).

27. Kossin, J. P. A global slowdown of tropical-cylcone translation speed. Nature 558, 104-107 (2018).

542 28. Zhang, G., Murakami, H., Knutson, T. R., Mizuta, R. \& Yoshida, K. Tropical cyclone 543 motion in a changing climate. Sci. Adv. 6, 1-8 (2020).

$54429 . \quad$ Yamaguchi, M., Chan, J. C. L., Moon, I. J., Yoshida, K. \& Mizuta, R. Global warming $545 \quad$ changes tropical cyclone translation speed. Nat. Commun. 11, 1-7 (2020).

546 30. Emanuel, K. Response of global tropical cyclone activity to increasing CO2: Results 547 from downscaling CMIP6 models. J. Clim. 34, 57-70 (2021).

548 31. Marsooli, R., Lin, N., Emanuel, K. \& Feng, K. Climate change exacerbates hurricane 
flood hazards along US Atlantic and Gulf Coasts in spatially varying patterns. Nat. Commun. 10, 1-9 (2019).

551 32. Helaire, L. T., Talke, S. A., Jay, D. A. \& Chang, H. Present and Future Flood Hazard in the Lower Columbia River Estuary: Changing Flood Hazards in the PortlandVancouver Metropolitan Area. J. Geophys. Res. Ocean. 125, 1-17 (2020).

$55433 . \quad$ Lee, C. Y., Camargo, S. J., Sobel, A. H. \& Tippett, M. K. Statistical-Dynamical downscaling projections of tropical cyclone activity in a warming climate: Two diverging genesis scenarios. J. Clim. 33, 4815-4834 (2020).

34. Bhatia, K., Vecchi, G., Murakami, H., Underwood, S. \& Kossin, J. Projected response of 558 tropical cyclone intensity and intensification in a global climate model. J. Clim. 31, 8281-8303 (2018).

35. Moftakhari, H. R., Schubert, J. E., Aghakouchak, A., Matthew, R. A. \& Sanders, B. F. Linking statistical and hydrodynamic modeling for compound flood hazard assessment in tidal channels and estuaries. Adv. Water Resour. 128, 28-38 (2019).

36. Ye, F. et al. Simulating storm surge and compound flooding events with a creek-toocean model: Importance of baroclinic effects. Ocean Model. 145, 101526 (2020). Galveston Bay during Hurricane Harvey. Sci. Total Environ. 747, 141272 (2020).

38. Gori, A., Lin, N. \& Smith, J. Assessing Compound Flooding from Landfalling Tropical Cyclones on the North Carolina Coast. Water Resour. Res. (2020). doi:10.1029/2019wr026788

39. Bilskie, M. V. et al. Enhancing Flood Hazard Assessments in Coastal Louisiana Through Coupled Hydrologic and Surge Processes. Front. Water 3, 1-19 (2021).

572 40. Kalnay, E. et al. The NCEP_NCAR 40-year reanalysis project. 1996.pdf. Bull. Am. $573 \quad$ Meteorol. Soc. 77, 437-472 (1996).

574 41. Lin, N., Emanuel, K., Oppenheimer, M. \& Vanmarcke, E. Physically based assessment of hurricane surge threat under climate change. Nat. Clim. Chang. 2, 462-467 (2012).

576 42. Lin, N., Emanuel, K. A., Smith, J. A. \& Vanmarcke, E. Risk assessment of hurricane storm surge for New York City. J. Geophys. Res. Atmos. 115, 1-11 (2010).

578 43. Feldmann, M., Emanuel, K., Zhu, L. \& Lohmann, U. Estimation of atlantic tropical 579 cyclone rainfall frequency in the United States. J. Appl. Meteorol. Climatol. 58, 1853- 
1866 (2019).

581 44. Holland, G. J. Tropical Cyclone Motion: Environmental Interaction Plus a Beta Effect. J.

$582 \quad$ Atmos. Sci. 40, 328-342 (1983).

583 45. Emanuel, K., DesAutels, C., Holloway, C. \& Korty, R. Environmental control of tropical cyclone intensity. J. Atmos. Sci. 61, 843-858 (2004).

46. Chavas, D. R., Lin, N., Dong, W. \& Lin, Y. Observed tropical cyclone size revisited. J. Clim. 29, 2923-2939 (2016).

47. Schenkel, B. A. et al. Lifetime evolution of outer tropical cyclone size and structure as diagnosed from reanalysis and climate model data. J. Clim. 31, 7985-8004 (2018).

48. Chavas, D. R. \& Lin, N. A model for the complete radial structure of the tropical cyclone wind field. Part II: Wind field variability. J. Atmos. Sci. 73, 3093-3113 (2016).

49. Knaff, J. A., Longmore, S. P. \& Molenar, D. A. An objective satellite-based tropical

593 50. Knutson, T. R. et al. Global projections of intense tropical cyclone activity for the late twenty-first century from dynamical downscaling of CMIP5/RCP4.5 scenarios. J. Clim. 28, 7203-7224 (2015).

51. Cannon, A. J. Multivariate quantile mapping bias correction: an $\mathrm{N}$-dimensional probability density function transform for climate model simulations of multiple variables. Clim. Dyn. 50, 31-49 (2018).

52. Cannon, A. J., Sobie, S. R. \& Murdock, T. Q. Bias correction of GCM precipitation by quantile mapping: How well do methods preserve changes in quantiles and extremes? J. Clim. 28, 6938-6959 (2015).

602 53. Tokdar, S. T. \& Kass, R. E. Importance sampling: A review. Wiley Interdiscip. Rev. 603 Comput. Stat. 2, 54-60 (2010).

604 54. Egbert, G. D. \& Erofeeva, S. Y. Efficient inverse modeling of barotropic ocean tides. J. Atmos. Ocean. Technol. 19, 183-204 (2002).

606 55. Emanuel, K. \& Rotunno, R. Self-stratification of tropical cyclone outflow. Part I: Implications for storm structure. J. Atmos. Sci. 68, 2236-2249 (2011).

608 56. Holland, G. An analytical model of wind and pressure profiles in hurricanes. Mon. $609 \quad$ Weather Rev. 108, 1212-1218 (1980).

610 57. Willmott, C. J. On the validation of models. Phys. Geogr. 2, 184-194 (1981). 
611 58. USGS. National Hydrography Dataset (ver. USGS National Hydrography Dataset Best 612 Resolution (NHD) for Hydrologic Unit (HU) 4. (2019). Available at:

613 https://www.usgs.gov/core-science-systems/ngp/national-hydrography/access-

614 national-hydrography-products. (Accessed: 10th September 2020)

615 59. Fagnant, C., Gori, A., Ensor, K. B., Sebastian, A. \& Bedient, P. B. Characterizing

616 spatiotemporal trends in extreme precipitation across the southern Texas coast. Nat.

617 Hazards (2020). doi:10.1007/s11069-020-04235-X

618 60. Little, C. M. et al. Joint projections of US East Coast sea level and storm surge. Nat.

619 Clim. Chang. 5, 1114-1120 (2015).

620 61. Coles, S. An Introduction to Statistical Modeling of Extreme Values. (Springer-Verlag, 621 2001).

622 62. Zheng, F., Westra, S., Leonard, M. \& Sisson, S. a. Modeling dependence between 623 extreme rainfall and storm surge to estimate coastal flooding risk. Water Resour. Res. 624 2050-2071 (2014). doi:10.1002/2013WR014616

625 63. A. G. Stephenson. evd: Extreme Value Distributions. R News 2, 31-32 (2002).

626 64. Zheng, F., Westra, S. \& Sisson, S. A. Quantifying the dependence between extreme 627 rainfall and storm surge in the coastal zone. J. Hydrol. 505, 172-187 (2013).

628 65. Wu, W. \& Leonard, M. Impact of ENSO on dependence between extreme rainfall and 629 storm surge. Environ. Res. Lett. 14, 124043 (2019).

630

631

632 


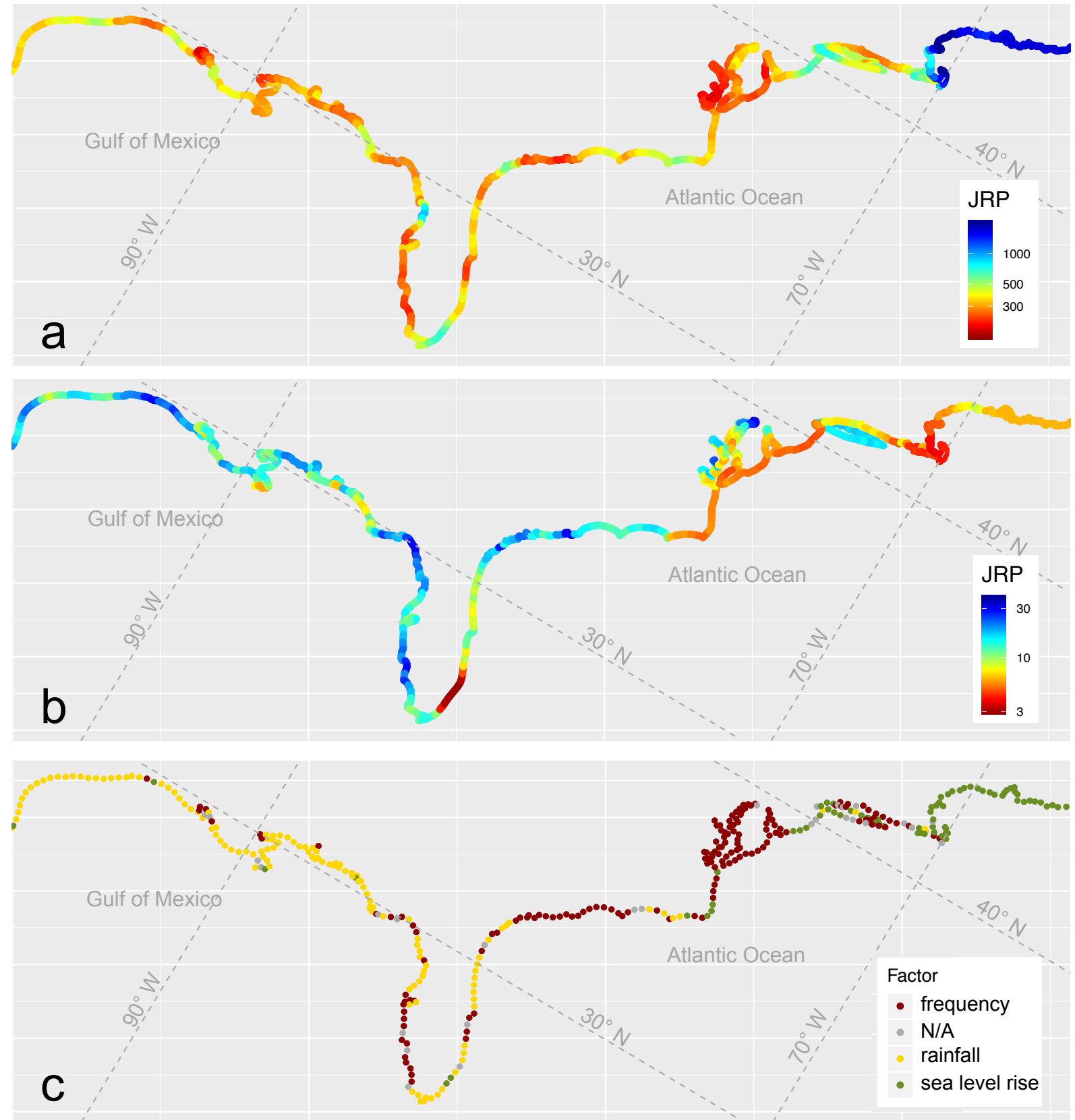

634 Figure 1: Joint return period of NCEP historical 100-yr rainfall and 100-yr sea level (JRP)

635 for (a) NCEP historical period, (b) future period (2070-2100) based on GCM

636 composite projection and 2100 SLR, and (c) largest single factor contributing to

637 increase in joint hazard or N/A if no single hazard is larger than others.

638

639

640 


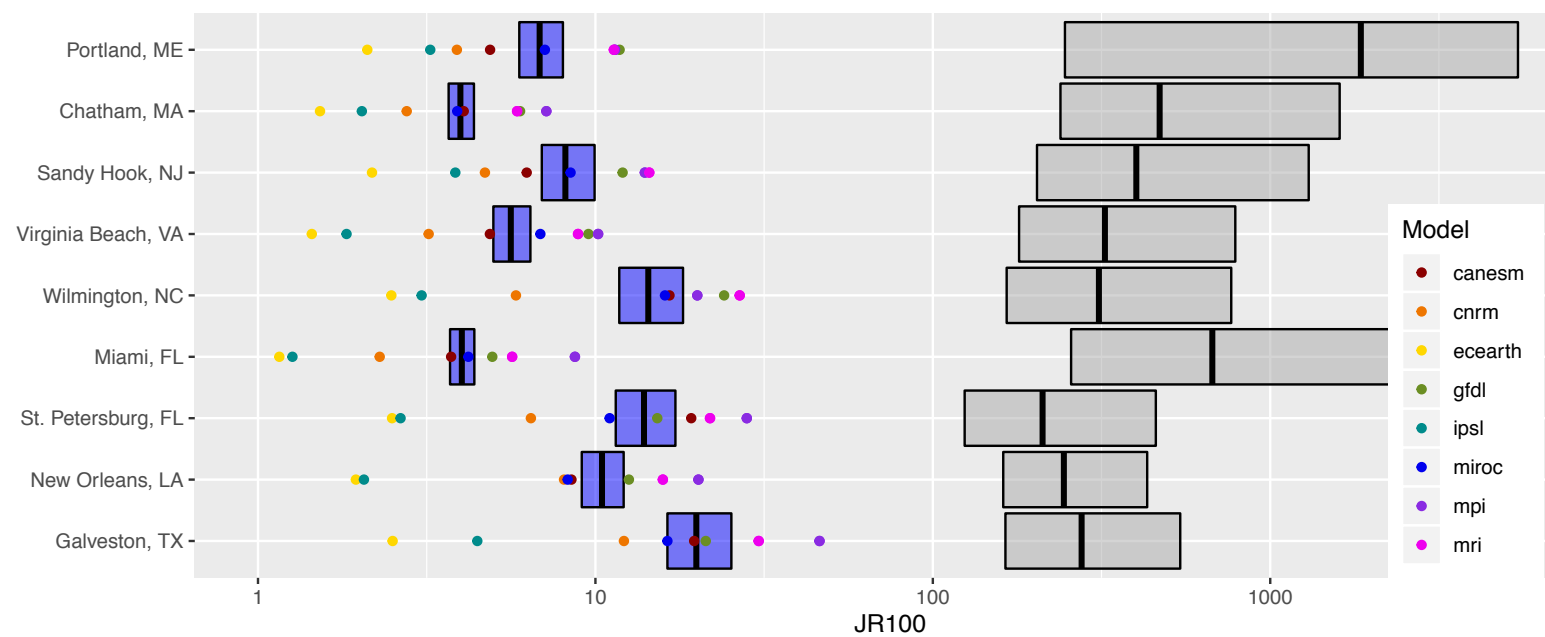

642 Figure 2: Historical and future JRP estimates and 95\% boot-strapped uncertainty bounds

643 for select locations under NCEP historical (gray) and GCM future composite (blue)

644 forcing. GCM model ensemble spread at each location for the future period (2070-

$645 \quad$ 2100) shown as colored dots.

646

647

648

649

650

651

652

653

654

655

656

657

658

659

660

661

662 


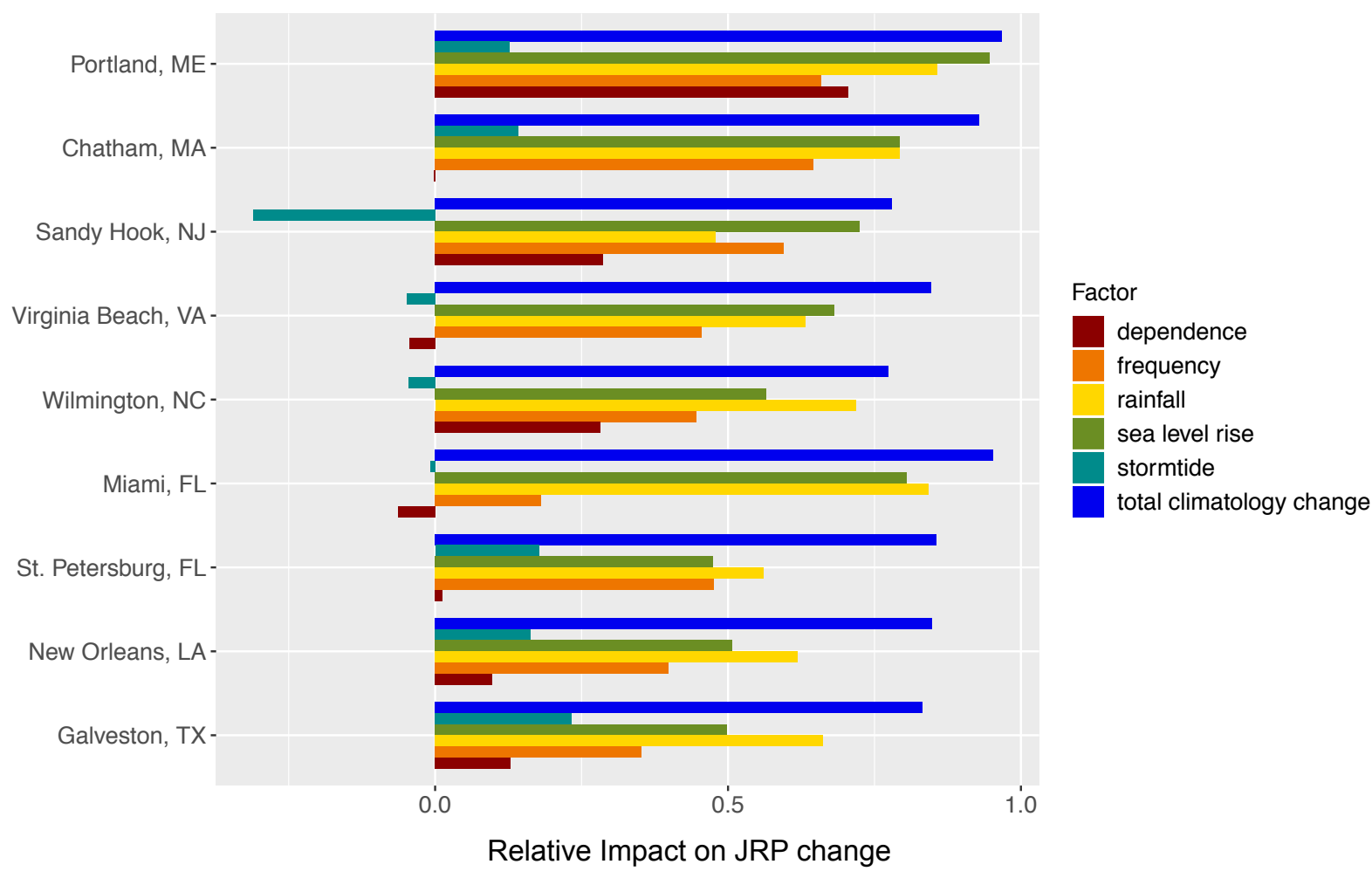

Figure 3: Relative impact of each single climate factor on JRP change and impact of total changes in TC climatology or sea level rise. Zero indicates no change in JRP compared to NCEP historical JRP and one indicates that the factor causes the entire change between historical and future JRP. Negative impact values indicate that the factor increases the JRP compared to historical best estimate (vertical black lines in Fig 2a). Note that the combined impact of all climate factors on JRP is highly non-linear and thus the sum of the relative impact of each single factor does not sum to one. 


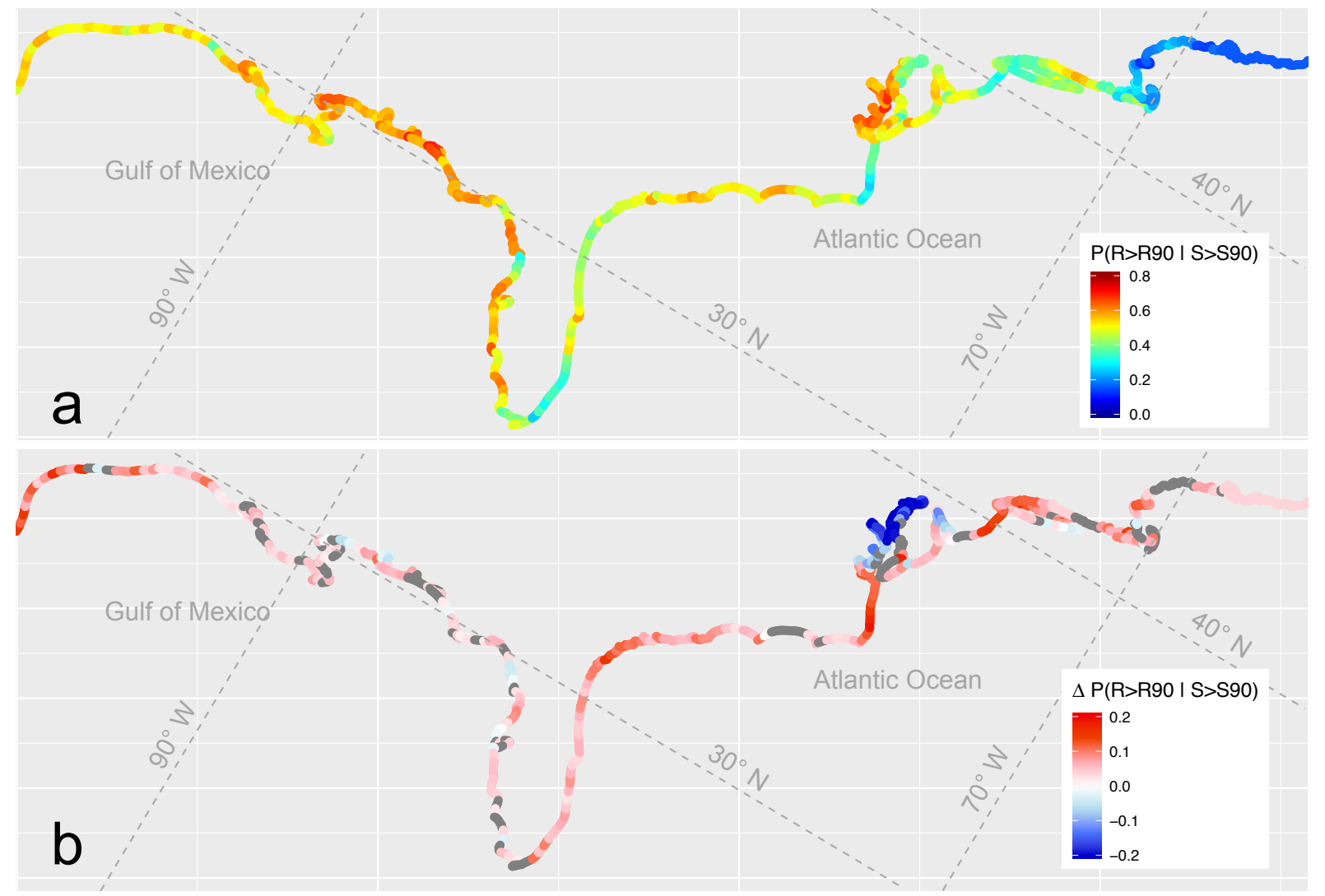

680

681 Figure 4: (a) Conditional probability of extreme rainfall (exceeding $90^{\text {th }}$ percentile) given

682 extreme storm tide (exceeding 90th percentile) in the historical period, and (b)

683 change in conditional probability of extreme rainfall due to future storm climatology.

684 Positive (negative) values indicate increase (decrease) in conditional probability.

685 Areas where fewer than six models agree on the sign of the change are depicted in

686 gray.

687

688

689

690

691

692

693

694

695 


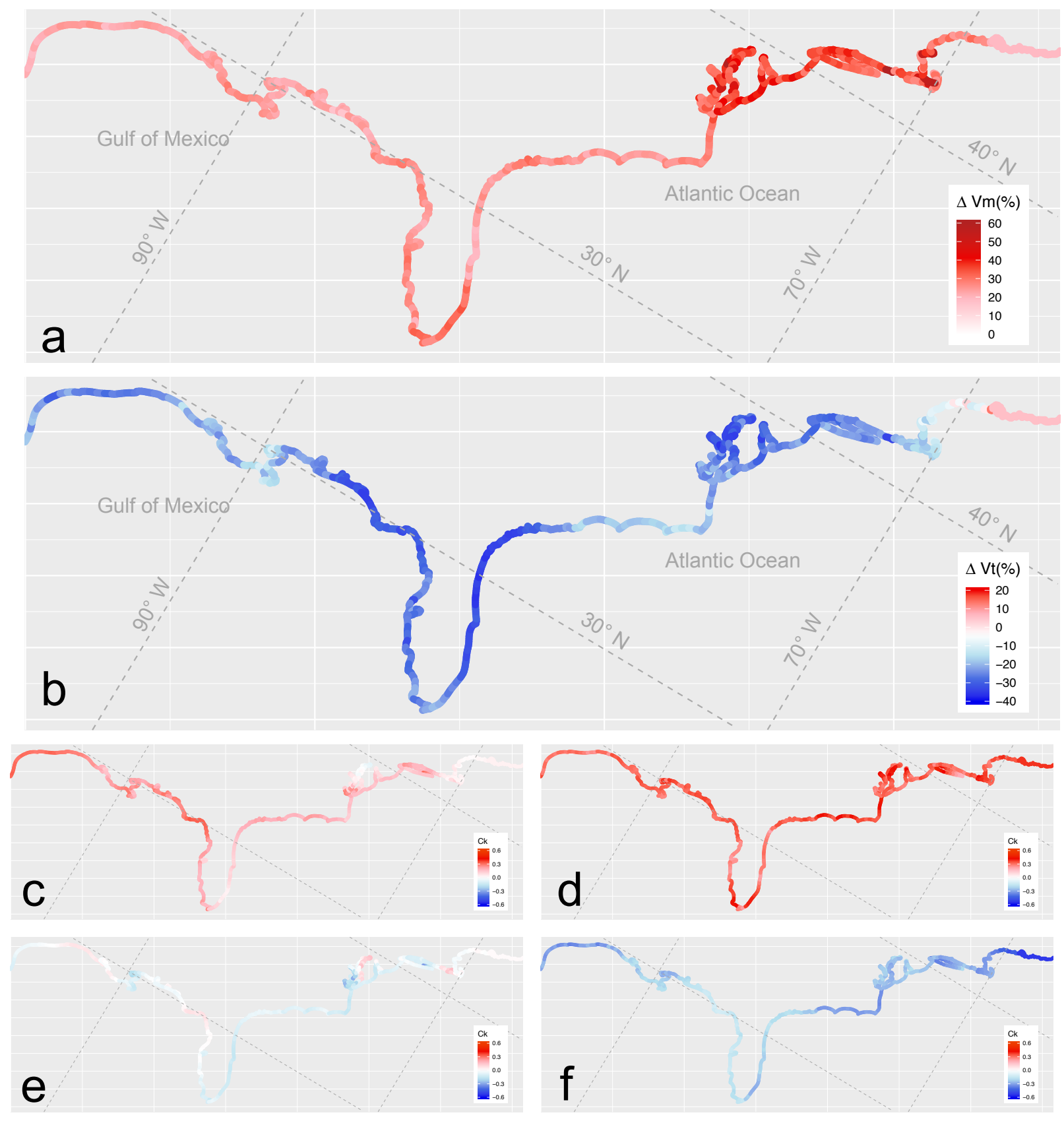

697 Figure 5: Change between future composite TC characteristics and historical characteristics for (a) $90^{\text {th }}$ percentile TC intensity (Vmax), and (b) median translation speed (Vt) of storms that exceed $90^{\text {th }}$ percentile intensity. Kendall correlation between Vmax and storm tide (c) or rainfall (d) and between Vt and storm tide (e) or rainfall (f). 


\section{Supplementary Files}

This is a list of supplementary files associated with this preprint. Click to download.

- SupplementaryInformation.docx 